\title{
Effectiveness of beta-tricalcium phosphate in comparison with other materials in treating periodontal infra-bony defects around natural teeth: a systematic review and meta-analysis
}

Reham AL Jasser ${ }^{1 *}$, Abdulelah AlSubaie ${ }^{2}$ and Fayez AlShehri ${ }^{2}$

\begin{abstract}
Background: Beta-tricalcium phosphate in regenerative surgery has shown promising results in terms of bone gain and new vital bone formation; however, several studies have contradicted this finding. The aim of this study was to evaluate the effectiveness of beta-tricalcium phosphate compared to other grafting materials in the regeneration of periodontal infra-bony defects.

Methods: Electronic database (Cochrane, MEDLINE, PubMed, Embase, Science Citation Index Expanded) and manual searches for related data were performed up until March 2020. The outcomes were pocket depth reduction, clinical attachment level gain, and amount of bone fill.

Results: Five studies were selected based on the inclusion criteria. Bone regeneration with beta-tricalcium phosphate was observed to be superior to that with debridement alone but showed comparable results to other bone graft materials in terms of pocket depth reduction, clinical attachment level gain, and bone fill. Regenerative procedures for periodontal infra-bony defects that used beta-tricalcium phosphate in combination with other growth factors yielded superior outcomes. The meta-analysis revealed that for cases with two-wall defects, the use of betatricalcium phosphate yielded statistically significant differences in pocket depth reduction and clinical attachment level gain, but not in bone fill.
\end{abstract}

Conclusions: Beta-tricalcium phosphate appears to be a promising material for use in periodontal infra-bony defect regeneration around natural teeth. However, randomized clinical trials with larger sample sizes and more controlled study designs are needed to support these findings.

Keywords: Beta-tricalcium phosphate, Intra-bony defect, Periodontal surgery, Regeneration, Bone fill, Pocket depth reduction, Clinical attachment gain

*Correspondence: raljasser@ksu.edu.sa

${ }^{1}$ Associate Professor, Department of Periodontics and Community

Dentistry, Dental College, King Saud University, PO Box 60169,

Riyadh 11545, Saudi Arabia

Full list of author information is available at the end of the article

\section{Background}

Tricalcium phosphate is found as four chemically polymorphs: $\alpha$, super- $\alpha, \gamma$, and $\beta$ [1]. Beta-tricalcium phosphate $(\beta-$ TCP) was introduced in 1973 by Driskell [2] as a material to treat bone defects caused by trauma. $\beta$-TCP is a bioceramic material used in the medical and dental field [3]. Animal studies have proven its usefulness in several dental procedures, such as pulp capping 
and apexification in endodontics [4], repair of cleft palates and orbital rim defects in maxillofacial surgery $[5,6]$, and repair of osseous lesions in periodontics [7]. $\beta$-TCP is a biocompatible $[4,6,8]$ alloplastic bone grafting material that is resorbable with osteoconductive properties [9]. Therefore, it is considered as a good alternative to autografts or allografts for certain grafting procedures. It has been shown to undergo complete resorption and is replaced by bone within a period of $0.5-1.5$ years [10] when applied to various bony defects, such as intraosseous defects around natural teeth, edentulous defective alveolar ridges, and maxillary sinuses $[9,11]$.

The amount of mature bone that this material can provide in a grafted area is crucial. When grafted sites were histologically evaluated, $\beta$-TCP particles were observed to be surrounded by and are in intimate contact with osteoid. Furthermore, fragments of mature bone appeared separate from the synthetic material with minimal traces of inflammation. This suggests that $\beta$-TCP undergoes complete resorption and replacement by mature bone. However, this process might take years to complete [12]. Several attempts have been made to measure the amount of mature bone formation with this grafting material over different periods of time. A histological study evaluating the re-osteointegration process of a bony defect around implants in the area of the distal surface of the first molar and the mesial surface of the second molar showed a bone gain of $1.90 \mathrm{~mm}$ and $1.41 \mathrm{~mm}$ around the first and second molars, respectively [13].

Kishore $\mathrm{T}$ et al. reported a mean bone fill (BF) of $3.6 \mathrm{~mm}$ and $4.4 \mathrm{~mm}$ with $\beta$-TCP alone after 6 and 9 months, respectively [14]. As such, this grafting material has shown promising results in grafting procedures, compared to the gold standard autografts and allografts. Saini et al. conducted a split-mouth design study comparing $\beta$-TCP alone and in combination with plateletrich plasma and observed linear BF with $\beta$-TCP alone [15]. When $\beta$-TCP was combined with the membrane, the BF was $3.9 \mathrm{~mm}$ and $4.2 \mathrm{~mm}$ after 6 and 9 months, respectively.

Several studies utilizing $\beta$-TCP alone or in combination with other grafting materials in several different surgical regenerative procedures have shown promising results for BF and new vital bone formation, in a manner that is comparable to that achieved with other bone grafting materials such as allografts and xenografts [16-18]. In contrast, some studies have contradicted previous statements. A study by Snyder et al. reported an inferior outcome with $\beta$-TCP, compared with other grafting materials [11]. Thus, the literature shows conflicting results and there is a lack of information regarding the exact amount of BF associated with different surgical regenerative procedures when using $\beta$-TCP. Therefore, the aim of this systematic review was to evaluate the use of $\beta$-TCP alone and combined with other substitutes for bone regeneration around natural teeth.

\section{Focused question}

What are the periodontal regenerative outcomes when using $\beta$-TCP as a grafting material (whether alone or in combination with growth factors), and how are they different from those with other grafting materials when used in guided tissue regeneration (GTR) of infra-bony defects around natural teeth?

\section{Methods}

\section{Study design}

We conducted a systematic review of studies focusing on the use of $\beta$-TCP in combination with other bone graft materials for the regeneration of bone defects around natural teeth. As currently recommended, we followed the PRISMA Statement checklist for reporting a systematic review [19].

\section{Registration}

The protocol for this systematic review was specified in advance and registered with the International Prospective Register of Systematic Reviews (PROSPERO) on 6/1/2020.

\section{Eligibility criteria for study inclusion}

To conduct the systematic review, we assessed all studies in which the primary objective was to evaluate the benefit of $\beta$-TCP combined with other bone grafts in GTR around natural teeth. Randomized clinical trials, case series, and case reports were eligible for inclusion. Thereafter, the eligibility criteria (by applying the PICO framework) were as follows:

Population: Patients with periodontal infra-bony defects (including 1,2, or 3 walls) around natural teeth.

Intervention: Graft material composed mainly of $\beta$-TCP.

Control: All other graft materials used to treat such defects.

\section{Outcomes:}

Primary: pocket depth reduction (PD reduction), clinical attachment level gain (CAL gain), and amount of BF.

Secondary: keratinized tissue width (KTW), gingival recession (GR), and soft tissue thickness change $(\Delta \mathrm{STT})$. 


\section{Search strategy}

A comprehensive three-step search strategy was established to identify studies for this systematic review. No language restrictions were applied. Electronic searches of the MEDLINE (via PubMed), EMBASE, and Cochrane, Science Citation Index Expanded databases and manual searches of unpublished data, academic theses, and journals were conducted up until March 2020. Additionally, the reference lists and trial registries were searched, and regulatory agency websites and manufacturers were queried. This search and subsequent review took a period of 6 months. The online database search was performed using the following search strategy prepared for MEDLINE: ((((Periodontal regeneration) OR infra bony defects) OR furcation defects) OR guided tissue regeneration) OR guided bone regeneration) OR bone augmentation $))))$ ) AND ((()(((bone fill) OR periodontal pocket) OR clinical attachment level) OR keratinized tissue) OR bone regeneration) OR soft tissue regeneration) OR recession) OR furcation fill)) )) )))) ((Tri calcium phosphate) OR calcium phosphate) OR synthograft).

\section{Selection of included studies}

Two independent reviewers (A.S and F.S) screened the titles, abstracts, and full texts of the papers that were identified. Disagreements between the reviewers were resolved through discussion until consensus was reached. Inter-reviewer agreement for the selection process was assessed using Cohen's Kappa score [20]. The reasons for excluding studies were recorded. Studies meeting the inclusion criteria underwent data extraction and synthesis.

\section{Data extraction}

A pre-designed form was developed to extract the following data: Author name(s); publication year and place; source of funding; conflict of interest; study design; sample size; follow-up period; source, selection, and description of the study population (including age, sex, race, ethnicity, and presence and characteristics of GR at baseline); definition and measurement method of the intervention; controls; outcomes; results and their variations; and risk-of-bias.

\section{Data synthesis}

The data were organized into evidence tables according to PRISMA guidelines [19], and a descriptive summary was created to determine the study's characteristics, quality, and results. Descriptive statistical analysis according to the mean values was used to evaluate the outcomes (Table 1).

\section{Quality and risk-of-bias assessment}

The methodological quality of the included studies was assessed and recorded into tables according to the PRISMA guidelines, focusing on the following points: (1) Method of randomization (e.g., the method used to generate the randomization sequence): (i) adequate, when random-number tables, a tossed coin, or shuffled cards were used; (ii) inadequate, when other methods were used, such as alternate assignment, hospital number, or odd/even date of birth; and (iii) unclear, when the method of randomization was not reported or explained. (2) Allocation concealment (e.g., how the randomization sequence was concealed from the examiners): (i) adequate, when examiners were kept unaware of the randomization sequence (e.g., using central randomization or opaque envelopes); (ii) inadequate, when other methods were used, such as alternate assignment or hospital number; and (iii) unclear, when the method was not reported or explained. (3) The blindness of examiners with regard to the treatment procedures used in the study period was assessed. (4) The completion of follow-up was based on the following question: Was the number of subjects at baseline and after the follow-up period reported? Additional assessments included the presence of explanations (reasons) for dropouts. Studies that did not report the completion of follow-up were excluded. (5) The similarity between groups at baseline. (6) Assessment of any analysis performed to control for confounding factors that can affect the final outcomes (Table 2). The risk-of-bias was graded as low, high, or unclear for each domain, based on the criteria defined in the Cochrane Handbook for Systematic Reviews of Interventions version 5.1.0 (Higgins and Green, 2011).

\section{Quantitative analysis}

Meta-analyses were performed for the three variables (PD reduction, CAL gain, and $\mathrm{BF}$ ). As these variables are quantitative (continuous), the mean and standard deviation were used to describe them. The standardized mean difference (SMD) was used as a summary pooled statistic, where pooled effects of $0.2,0.5$, and 0.8 represented small, medium, and large effects, respectively. Student's t-test for a single sample was used to determine the statistical significance of SMD. Cochran's Q was used to identify the heterogeneity in the pooled data, and $\mathrm{I}^{2}$ values were used to observe the percentage of total variation across the studies included in the meta-analysis. A cut-off $\mathrm{I}^{2}$ value $>50 \%$ was used to rule out the higher levels of unexplained variability in the effect sizes. Pooled estimates were 
Table 1 Qualitative description of the included studies

\begin{tabular}{|c|c|c|c|c|c|c|}
\hline Name of author & Country & Population & Intervention & Follow-up & Comparison & Outcomes \\
\hline Strub et al. 1979 & Switzerland & $\begin{array}{l}\text { Patients } 8 \\
\text { Age } 28-55 \text { years } \\
\text { Gender } 5 \mathrm{M}, 3 \mathrm{~F} \\
\text { Bony defects } 47 \\
\text { Defect Type 1-, 2-, } \\
\text { 3-Wall defects or } \\
\text { horizontal bone loss } \\
\text { Pre-surgical Prepara- } \\
\text { tion } \\
\text { OHI* } \\
\text { SRP* } \\
\text { Occlusal adjustment } \\
\text { Splinting } \\
\text { Re-evaluation after } \\
4-6 \text { weeks } \\
\text { Antibiotic use } 4 \text { million } \\
\text { IU oral penicillin } \\
1 \text { day pre-surgery }\end{array}$ & $\begin{array}{l}\text { TCP* } \\
\text { Form } \\
\text { TCP was mixed with } \\
\text { sterile distilled water } \\
\text { ( } 38.5 \% \text { powder to } \\
61.5 \% \text { water) to } \\
\text { form a paste }\end{array}$ & 12 months & Frozen allogenic graft & $\begin{array}{l}\text { Primary outcomes } \\
\text { PD* reduction } \\
\text { (TCP): } 1.8 \mathrm{~mm} \\
\text { (allograft): } 2.0 \mathrm{~mm} \\
\text { Re-entry BF* } \\
\text { (TCP): } 1.2 \mathrm{~mm} \\
\text { (Allograft): } 1.5 \mathrm{~mm} \\
\text { Secondary outcomes } \\
\text { Radiographic BF } \\
\text { (TCP): } 1.05 \mathrm{~mm} \\
\text { (Allograft): } 0.9 \mathrm{~mm} \\
\text { Residual pocket deeper } \\
\text { than } 3 \mathrm{~mm} \text { (TCP) } \\
\text { 38\% } \\
\text { (Allograft): } 22 \%\end{array}$ \\
\hline Snyder AJ et al., 1984 & USA & $\begin{array}{l}\text { Patients } 10 \\
\text { Age Unknown } \\
\text { Gender Unknown } \\
\text { Bony defects } 10 \\
\text { Defect type 1- or } \\
\text { 2-wall, furcation } \\
\text { areas } \\
\text { Pre-surgical prepara- } \\
\text { tion } \\
\text { Initial-phase therapy } \\
\text { Occlusal analysis } \\
\text { Antibiotics Tetracycline } \\
250 \text { mg tablets, q.i.d } \\
10 \text { days post-surgery }\end{array}$ & $\begin{array}{l}\text { TCP } \\
\text { Form } \\
\text { Die-pressed to form } \\
\text { discs } 2 \text { inches in } \\
\text { diameter } \times 1 / 8 \text { - } \\
\text { inch thick and fired } \\
\text { at } 2000^{\circ} \mathrm{F} \text { for } 2 \mathrm{~h} \text {. } \\
\text { The discs were } \\
\text { then crushed in } \\
\text { an alumina mortar } \\
\text { and pestle, with the } \\
\text { resulting powder } \\
\text { being sieved } \\
\text { to recover the } \\
200 /+325 \text { mesh } \\
\text { size fraction }\end{array}$ & 18 months & None & $\begin{array}{l}\text { Primary outcomes } \\
\text { PD reduction } 3.6 \mathrm{~mm} \\
C A L^{*} \text { gain } 1.2 \mathrm{~mm} \\
\text { Re-entry BF } 2.8 \mathrm{~mm}\end{array}$ \\
\hline $\begin{array}{l}\text { Zefiropoulos GG et al., } \\
2007\end{array}$ & Germany & $\begin{array}{l}\text { Patients } 64 \\
\text { Age } 30-71 \text { years } \\
\text { Gender } 31 \mathrm{M}, 34 \mathrm{~F} \\
\text { Smoking status } \\
28 \mathrm{~S}^{*}, 37 \mathrm{NS}^{*} \\
\text { Bony defects } 93 \\
\text { Defect type } 2 \text { or } 3 \text { walls } \\
\text { Pre-surgical Prepara- } \\
\text { tion } \\
\text { Non-surgical therapy } \\
\text { Re-evaluation } \\
\text { Antibiotics } \\
\text { Diclofenac } 100 \text { mg } \\
\text { per day for } 4 \text { days, } \\
\text { started } 1 \text { day pre- } \\
\text { surgery }\end{array}$ & $\mathrm{HA} / \mathrm{b}-\mathrm{TCP}+\mathrm{ASB}$ * & 12 months & $\begin{array}{l}A S B^{*} \\
A S B+B D X^{*}\end{array}$ & $\begin{array}{l}\text { Primary outcomes } \\
\text { CAL gain } \\
\text { (HA/b-TCP + ASB): } \\
3.2 \mathrm{~mm} \\
\text { (ASB): } 3.4 \mathrm{~mm} \\
\text { (BDX): } 3.2 \mathrm{~mm} \\
\text { Re-entry BF } \\
\text { (HA/b-TCP + ASB): } \\
1.6 \mathrm{~mm} \\
\text { (ASB): } 2.8 \mathrm{~mm} \\
\text { (BDX): } 1.5 \mathrm{~mm} \\
\text { Secondary outcomes } \\
\text { BOP* reduction } \\
\text { (HA/b-TCP + ASB): } \\
\text { 13.8\% } \\
\text { (ASB): } 14.7 \% \\
\text { (BDX): } 20.0 \% \\
\text { PLI*reduction } \\
\text { (HA/b-TCP + ASB): } \\
27.6 \% \\
\text { (ASB): } 26.5 \% \\
\text { (BDX): } 30.0 \% \\
\text { RBG*percentage } \\
\text { (HA/b-TCP+ASB): } \\
82.3 \% \\
\text { (ASB): } 69.3 \% \\
\text { (BDX): } 83.3 \%\end{array}$ \\
\hline
\end{tabular}


Table 1 (continued)

\begin{tabular}{|c|c|c|c|c|c|c|}
\hline Name of author & Country & Population & Intervention & Follow-up & Comparison & Outcomes \\
\hline Rajesh JB et al., 2009 & India & $\begin{array}{l}\text { Patients } 60 \\
\text { Age } 20 \text { - } 45 \text { years } \\
\text { Gender Not men- } \\
\text { tioned } \\
\text { Bony defects } 60 \\
\text { Defect types } 2 \text { or } 3 \\
\text { walls } \\
\text { Pre-surgical prepara- } \\
\text { tion } \\
\text { OHI* } \\
\text { SRP* } \\
\text { Occlusal adjustment } \\
\text { Re-evaluation after } \\
4 \text { weeks } \\
\text { Antibiotics Doxycy- } \\
\text { cline } 100 \text { mg, BID for } \\
\text { the } 1 \text { st day followed } \\
\text { by } 100 \text { mg OD for } \\
5 \text { days }\end{array}$ & $\begin{array}{l}\text { CPC } \\
\text { Form } \\
\text { Chitra Calcium Phos- } \\
\text { phate Cement in } \\
\text { the form cement }\end{array}$ & 12 months & $\begin{array}{l}\text { Debridement only } \\
\text { (Deb) } \\
\text { Hydroxyapatite } \\
\text { cement granules } \\
\text { (HA) }\end{array}$ & $\begin{array}{l}\text { Primary outcomes } \\
\text { PD reduction } \\
\text { (CPC): } 6.20 \mathrm{~mm} \\
\text { (HA): } 4.05 \mathrm{~mm} \\
\text { (Deb): } 2.95 \mathrm{~mm} \\
\text { CAL gain } \\
\text { (CPC): } 5.80 \mathrm{~mm} \\
\text { (HA): } 3.55 \mathrm{~mm} \\
\text { (Deb): } 2.30 \mathrm{~mm} \\
\text { Secondary outcome } \\
\text { GR* reduction } \\
\text { (CPC): } 0.15 \mathrm{~mm} \\
\text { (HA): } 0.15 \mathrm{~mm} \\
\text { (Deb): } 0.20 \mathrm{~mm}\end{array}$ \\
\hline Sukumar S et al., 2010 & Czech Republic & $\begin{array}{l}\text { Patients } 21 \\
\text { Age } 21-53 \text { years } \\
\text { Gender } 8 \mathrm{M}, 13 \mathrm{~F} \\
\text { Smoking status } 7 \mathrm{~S} \text {, } \\
14 \mathrm{NS} \\
\text { Bony defects } 39 \\
\text { Defect Types } 2 \text { or } 3 \\
\text { walls } \\
\text { Pre-surgical prepara- } \\
\text { tion } \\
\text { OHI* } \\
\text { SRP* } \\
\text { Elimination of local } \\
\text { factors } \\
\text { Occlusal adjustment } \\
\text { Re-evaluation after } \\
2 \text { weeks } \\
\text { Antibiotics Amoxicil- } \\
\text { lin } 250 \text { mg with } \\
\text { clavulanic acid } \\
125 \text { mg or clarithro- } \\
\text { mycin } 500 \text { mg) } \\
\text { were prescribed } \\
\text { to the patients for } \\
7-14 \text { days }\end{array}$ & $\begin{array}{l}\mathrm{TCP} / \mathrm{CaSO}_{4}{ }^{*} \\
\text { Form } \\
\text { Composite mate- } \\
\text { rial consisting of } \\
\text { beta-tricalcium } \\
\text { phosphate + cal- } \\
\text { cium sulfate }\end{array}$ & 12 months & None & $\begin{array}{l}\text { Primary outcomes } \\
\text { PD reduction } \\
\left(\mathrm{TCP} / \mathrm{CaSO}_{4}\right): 1.98 \mathrm{~mm} \\
\text { CAL gain } \\
\left(\mathrm{TCP} / \mathrm{CaSO}_{4}\right): 1.68 \mathrm{~mm} \\
\text { Secondary outcomes } \\
\text { GR reduction: } \\
\left(\mathrm{TCP}_{\mathrm{CaSO}}\right): 0.31 \mathrm{~mm}\end{array}$ \\
\hline
\end{tabular}

OHI: oral hygiene instruction; SRP: scaling and root planing; TCP: tricalcium phosphate; PD: pocket depth; BF: bone fill; CAL: clinical attachment level; S: smoker; NS: non-smoker; HA: hydroxyapatite; ASB: autogenous spongiosa; BDX: bovine-derived xenograft; BOP: bleeding on probing; PLI: plaque index by Silness and Loe; CPC: cetyl pyridinium chloride; $\mathrm{GR}$ : gingival recession; $\mathrm{CaSO}_{4}$ : calcium sulfate

obtained using the fixed-effect and random-effect models. A $p$ value of $\leq 0.05$ and $95 \%$ confidence intervals were used to report the statistical significance and precision of the estimates. Graphical representation of results is shown using forest plots (overall effect using both fixed-and random-effect models) for the studies included in the meta-analysis. The analysis was performed using MedCalc for Windows version 15.0 (MedCalc Software, Ostend, Belgium).

\section{Results}

Reviewers' agreement and kappa score

Electronic searches yielded 74 articles, of which 10 were selected for full-text evaluation after screening their titles and abstracts. Five articles were further excluded, and the reasons for exclusion are listed in Fig. 1. The $k$ value for inter-reviewer agreement for potentially relevant articles was 0.91 for full-text article reviewing, indicating an "almost perfect" agreement between the two reviewers (Fig. 1). 
Table 2 Risk-of-bias assessment of the included studies

\begin{tabular}{|c|c|c|c|c|c|c|c|}
\hline Authors/year & Randomization & Blinding & $\begin{array}{l}\text { Incomplete } \\
\text { outcome } \\
\text { data }\end{array}$ & $\begin{array}{l}\text { Selective } \\
\text { outcome } \\
\text { reporting }\end{array}$ & $\begin{array}{l}\text { Similarity } \\
\text { of } \\
\text { groups at } \\
\text { baseline }\end{array}$ & $\begin{array}{l}\text { Control of } \\
\text { confounding and } \\
\text { interaction }\end{array}$ & Conflict of interest \\
\hline Strub JR et al., 1979 & No & No & No & No & $\begin{array}{l}\text { Yes, split- } \\
\text { mouth } \\
\text { design }\end{array}$ & No & None \\
\hline $\begin{array}{l}\text { Snyder AJ et al., } \\
\quad 1984\end{array}$ & No & No & No & No & $\mathrm{N} / \mathrm{A}$ & No & None \\
\hline $\begin{array}{l}\text { Zefiropoulos GG } \\
\text { et al., } 2007\end{array}$ & No & Yes, single blinding & Yes, CAL gain & No & No & No & None \\
\hline $\begin{array}{l}\text { Rajesh JB et al., } \\
2009\end{array}$ & $\begin{array}{l}\text { Yes, random- } \\
\text { number table } \\
\text { method }\end{array}$ & No & No & No & No & No & $\begin{array}{l}\text { Yes, study was } \\
\text { supported by } \\
\text { the graft material } \\
\text { company* }\end{array}$ \\
\hline $\begin{array}{l}\text { Sukumar S et al., } \\
2010\end{array}$ & No & No & No & No & N/A & No & None \\
\hline
\end{tabular}

CAL clinical attachment level

*Sree Chitra Tirunal Institute for Medical Sciences and Technology

\section{Study design and patient features}

Five studies were included, as shown in Table 1. The studies were published between 1979 and 2010 in the following countries: Switzerland, USA, German, India, and the Czech Republic. Four were prospective studies [11, 21-23], while one was retrospective [24]. One study used a split-mouth design to compare $\beta$-TCP versus allografts [21]. The total number of participants included in the five studies was $171[11,21-24]$. The participants' ages ranged from 20 to 71 years. The total number of treated sites was 254. The types of bone defects included 1-, 2-, and 3-wall defects. While patient sex was not specified in two studies $[11,23]$, the remaining three studies reported a total of 50 females and 44 males [21, 22, 24]. The smoking status of participants was not defined in three studies $[11,21,23]$. The study by Zafiropoulos et al. [22] defined smoking status by categorizing participants who smoked 10 cigarettes or more as a smoker, and those who smoked less than 10 cigarettes as non-smokers. The number of smokers in that study was 28 , while the number of nonsmokers was 37 . However, they did not consider smoking status during data analysis, and the two groups were pooled together, justifying that the total sample size and the number of smokers were small. [22]. The study by Sukumar et al. mentioned that 7 participants were medium smokers; however, they did not provide a clear definition of the smoking status. The follow-up period was 12 months in three studies, 18 months in one study, and not applicable in one study [24].

\section{Pre-surgical preparation}

The study by Strub et al. considered the initial-phase therapy, which consisted of oral hygiene instructions, scaling and root planing, occlusal adjustment, splinting, and re-evaluation after 4-6 weeks [21]. The study by Snyder et al. involved initial-phase therapy and occlusal analysis [11]. The trial by Zafiropoulos et al. included initial-phase therapy and re-evaluation [22]. Furthermore, in the study by Rajesh et al., oral hygiene instructions, scaling and root planing, occlusal adjustment, and re-evaluation after 4 weeks were performed [23]. Similarly, the study by Sukumar et al. described oral hygiene instructions, scaling and root planing, elimination of local factors, occlusal adjustment, and re-evaluation after 2 weeks [24].

\section{Types of interventions}

Strub et al. used $\beta$-TCP mixed with sterile distilled water in a ratio of $38.5 \%$ powder to $61.5 \%$ water, yielding a paste form [21]. Snyder et al. converted TCP to powder form by a specific preparation protocol [11]. Zafiropoulos et al. used biphasic calcium phosphate (a mixture of $60 \%$ hydroxyapatite (HA) and $40 \% \beta$-TCP) mixed with autogenous spongiosa (ASB) bone graft in the particulate form [22]. Rajesh et al. utilized Chitra calcium phosphate cement as an intervention in a putty form [23]. In the study by Sukumar et al., the intervention group received $\beta$-TCP with calcium sulfate, and the material was placed in a putty form (based on the manufacturer's instructions) [24].

\section{Comparison groups}

Three studies compared different types of bone grafts used to fill the defects. Strub et al. compared TCP powder to frozen allogenic bone [21]. Zafiropoulos et al. 


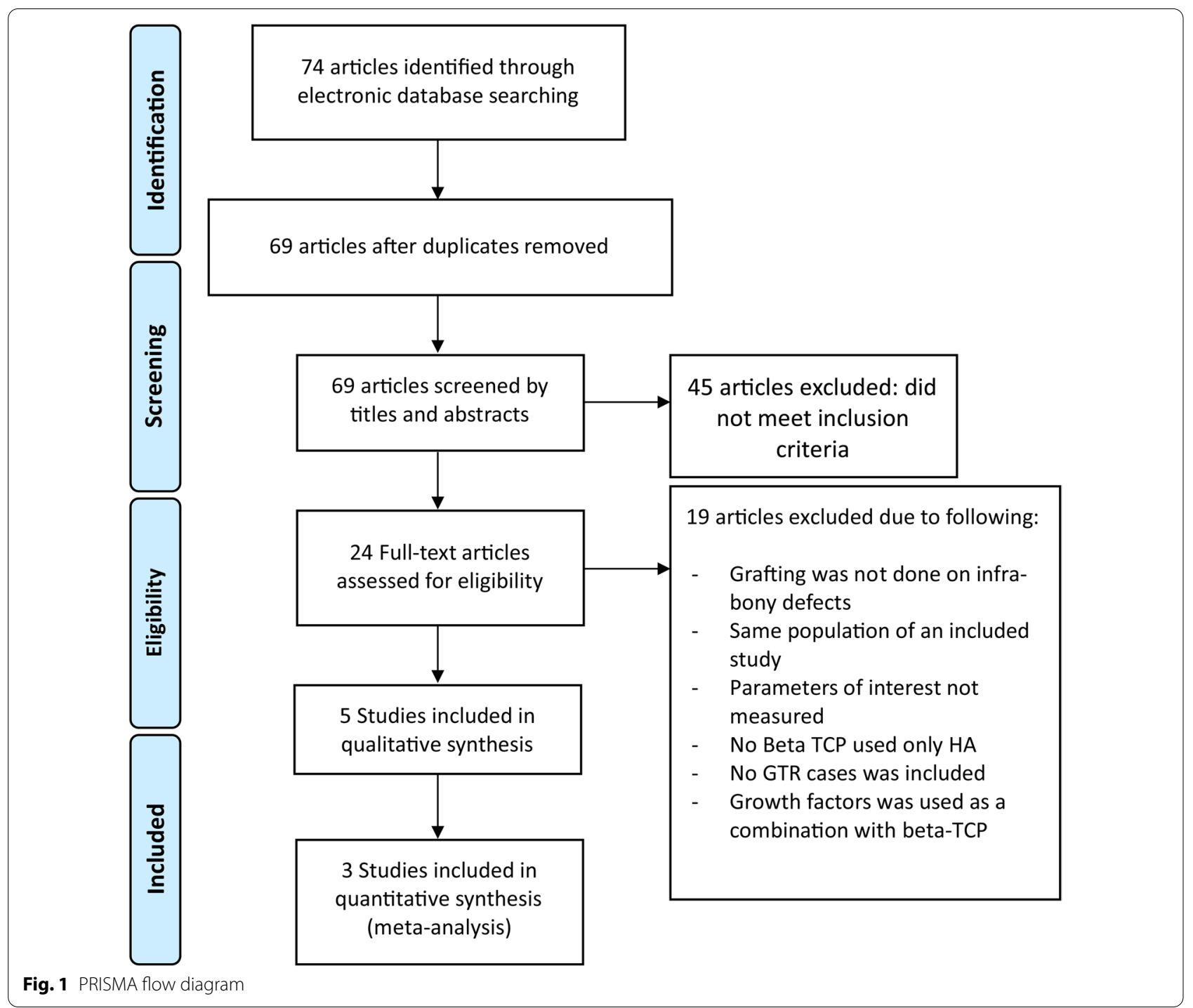

compared ASB alone, ASB combined with $\mathrm{HA} / \beta-\mathrm{TCP}$, or ASB combined with bovine-derived xenograft (BDX) [22]. Finally, Rajesh et al. compared calcium phosphate cement with HA cement and used debridement alone as a control group [23].

\section{Surgical approach}

In the study by Strub et al., a small palatal full-thickness flap was raised, followed by granulation tissue removal from the bony defect with root planing. Bleeding was induced in the defect area followed by placement of the $\beta$-TCP/frozen allogenic graft [21]. In the trial conducted by Snyder et al., an internal bevel incision with a buccal and lingual full-thickness flap was raised. Bone defects were debrided with root planing. Then, intra-marrow penetration was performed, and tricalcium phosphate cement was grafted [11]. Zafiropoulos et al. performed an intrasulcular incision with a full-thickness flap along with a vertical incision when needed. Granulation tissue was removed, and root planing was performed. Root surfaces adjacent to the defect were conditioned with tetracycline suspension $(100 \mathrm{mg} / \mathrm{mL})$. All autogenous bone graft materials were harvested from the retromolar area. ASP alone, ASP mixed with BDX, or ASP mixed with synthetic composite $(\beta-\mathrm{TCP}+\mathrm{HA})$ were placed. The augmented areas were covered with a collagen membrane [22]. Rajesh et al. performed an intrasulcular incision with a full-thickness flap, debrided the defect areas, and performed root planing. Root surfaces adjacent to the defect were conditioned with tetracycline suspension $(100 \mathrm{mg} / \mathrm{mL})$ and bone graft materials were placed. [23]. Finally, Sukumar et al. performed a crevicular incision with a facial and lingual full-thickness flap and vertical incision as needed, followed by root debridement 
and granulation tissue removal. Root surface conditioning was performed using $2.5 \%$ tetracycline hydrochloride, and TCP/calcium sulfate was packed into the defects [24].

\section{Antibiotic use}

Among the studies that used pre-surgical antibiotic protocols, Strub et al. prescribed penicillin 4 million IU orally 1 day before surgery [21], while Zafiropoulos et al. (2007) prescribed antibiotics with $0.1 \%$ chlorhexidine mouthwash 1 day before the surgery. [22]. Strub et al. used $0.2 \%$ chlorhexidine mouthwash twice a day for 2 weeks [21]; Snyder et al. administered tetracycline tablets $250 \mathrm{mg}$ four times a day for 10 days [11]; Zafiropoulos et al. used $0.1 \%$ chlorhexidine mouthwash two times a day for 3 weeks [22]; Rajesh et al. administered doxycycline $100 \mathrm{mg}$ two times a day for the first day followed by $100 \mathrm{mg}$ once a day for 5 days, with $0.2 \%$ chlorhexidine mouthwash [23]; and Sukumar et al. prescribed augmentin $375 \mathrm{mg}$ or clarithromycin $500 \mathrm{mg}$ for 7-14 days, followed by application of hydrogen peroxide 3\% during suture removal after 2 weeks and Listerine mouthwash for 2 weeks [24].

\section{Post-operative management}

In the trial conducted by Strub et al., periodontal dressing and cyanoacrylate tissue adhesive were placed [21]. Snyder et al. placed only periodontal dressing [11]. Zafiropoulos et al. administered oral diclofenac $100 \mathrm{mg}$ per day for 4 days [22]. Rajesh et al. placed a non-eugenol periodontal dressing for one week with ibuprofen $400 \mathrm{mg}$ t.i.d. for 3 days [23].

\section{Risk-of-bias assessment}

The results of bias assessment among the included studies are presented in Table 2. All studies obtained a low score in quality analysis (Fig. 2). Randomization and

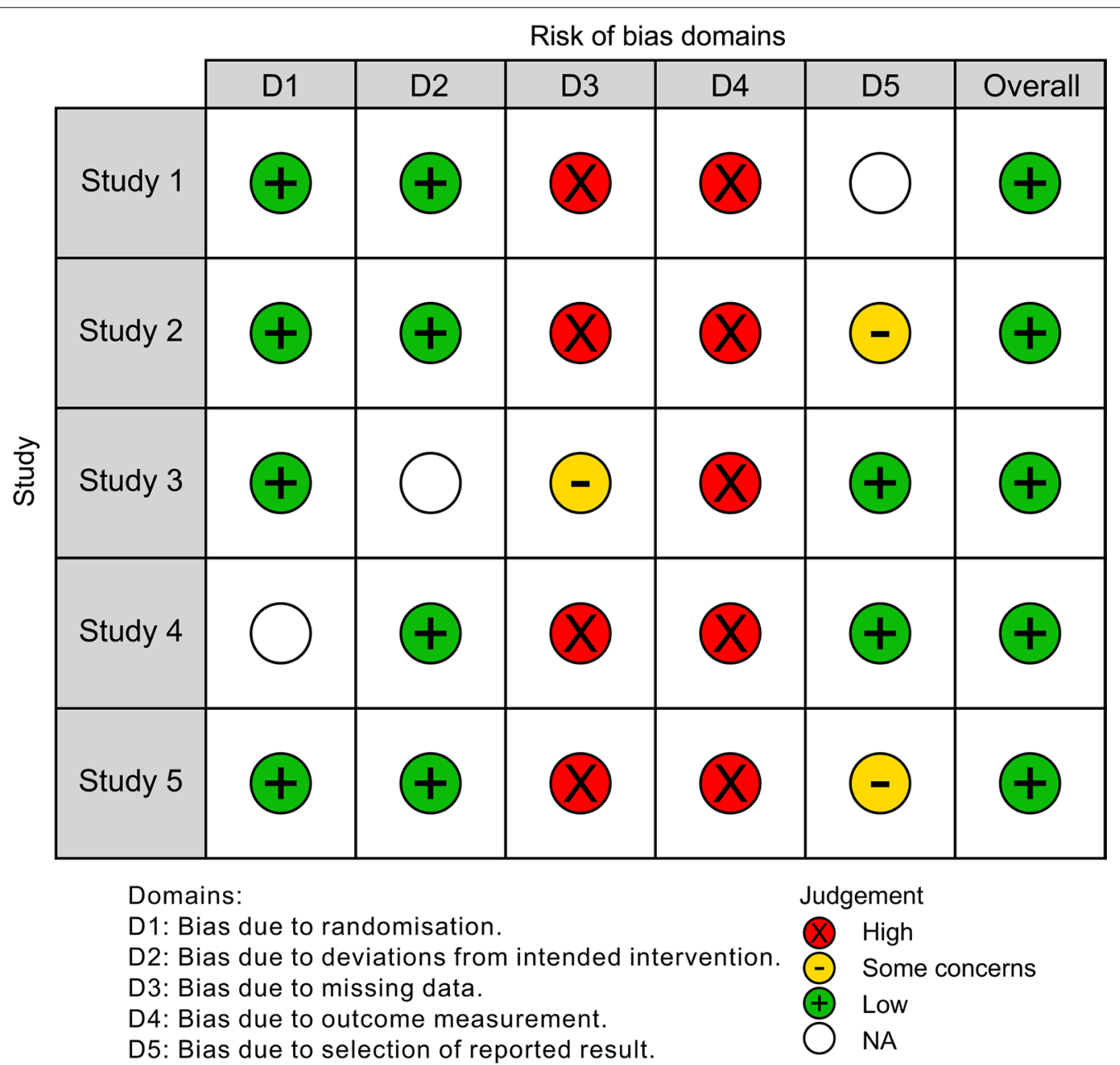

Fig. 2 Risk-of-bias assessment (Traffic Light Plot). Overall, all the included studies showed low risk-of-bias 
conflict of interest were reported in the study by Rajesh et al. [23]. Single blinding and incomplete outcome data were present in the study by Zafiropoulos et al. [22]. Details regarding the group similarity at baseline were not mentioned in the studies by Snyder et al. [11] and Sukumar et al. [24] (Fig. 2).

\section{Outcomes measured}

\section{Primary outcomes}

$P D$ reduction Strub et al. compared frozen allogenic graft versus TCP powder and observed a net change of 2 $\mathrm{mm}$ for the allogenic graft, with $22 \%$ of the cases showing PD reduction greater than $3 \mathrm{~mm}$; in the TCP group, the net change was $1.8 \mathrm{~mm}$, with $38 \%$ of the cases showing PD reduction greater than $3 \mathrm{~mm}$ [21]. Snyder et al. reported a 3.6- $\mathrm{mm}$ PD reduction for the TCP treatment, with no group for comparison [11]. Rajesh et al. reported that PD reduction with cetyl pyridinium chloride (CPC), HA, and debridement alone was $6.2 \mathrm{~mm}, 4.05 \mathrm{~mm}$, and $2.95 \mathrm{~mm}$, respectively [23]. Sukumar et al. reported a PD reduction of $1.98 \mathrm{~mm}$ for TCP, with no comparison group [24].

CAL gain Snyder et al. noted a net CAL gain of $1.2 \mathrm{~mm}$ for TCP, with no comparison group [11]. Zafiropoulos et al. observed that the net CAL gain for the HA/ $\beta$-TCP + ASB, ASB alone, and ASB + BDX groups were 3.2, 3.4, and $3.2 \mathrm{~mm}$, respectively. However, they did not compare the CAL results among the three groups [22]. Sukumar et al. reported a net CAL gain of $1.68 \mathrm{~mm}$ for TCP, with no comparison group [24].

$B F \quad$ Strub et al., at re-entry, noted a $1.2-\mathrm{mm}$ gain at the TCP-treated site, while the gain for the allogenic group was $1.5 \mathrm{~mm}$ [21]. Zaiforpoulos et al. reported a gain of 1.6 $\mathrm{mm}$ for $\mathrm{HA} / \beta$-TCP + ASB, $2.8 \mathrm{~mm}$ for ASB alone, and 1.5 $\mathrm{mm}$ for ASB + BDX [22].

\section{Secondary outcomes:}

$G R$ reduction Rajesh et al. observed that the GR reduction was $0.15 \mathrm{~mm}$ for CPC, $0.15 \mathrm{~mm}$ for HA, and $0.2 \mathrm{~mm}$ for the debridement group [23]. Sukumar et al. (2010) reported a $0.31-\mathrm{mm}$ increase in GR for the TCP group [24].

Meta-analysis results

\section{Two-wall infra-bony defects:}

For the outcome variable "PD reduction," the statistical significance was assessed by combining the difference in its mean values extracted from 2 studies [21, 23], both of which compared this variable between two groups. The results showed a statistically significant difference favoring $\beta$-TCP in the SMD values with the fixed-effect but not with the random-effect criteria $(\mathrm{t}=3.730, p=0.001$; $\mathrm{t}=1.844, p=0.075$, respectively). Cochran's $\mathrm{Q}$ value was not statistically significant $(\mathrm{Q}=3.707, p=0.0542)$, and the $\mathrm{I}^{2}$ value $(73.02 \%)$ was high but not statistically significant, which implies the absence of heterogeneity in the two studies included in the analysis. Hence, the pooled SMD obtained by the fixed-effect criteria was used to infer a significant difference in the mean values of $\mathrm{PD}$ reduction between the two groups $(\mathrm{SMD}=1.555$, $\mathrm{t}=3.730, p=0.001)$. The overall effect (1.555) was large (Table 3). The corresponding forest plot for PD reduction shows the effect sizes of each of the two studies and the combined effect size by the fixed- and random effects models (Fig. 3a).

For another outcome variable "CAL gain," the results again showed a statistically significant difference favoring $\beta$-TCP in the SMD values obtained by the fixed-effect but not by the random-effect criteria $(\mathrm{t}=2.119, p=0.042$; $\mathrm{t}=0.617, p=0.542$, respectively). Cochran's $\mathrm{Q}$ value was statistically significant $(\mathrm{Q}=9.499, p=0.002)$ and the $\mathrm{I}^{2}$ value $(89.47 \%)$ was high and statistically significant, which indicated heterogeneity in the two studies included in the analysis. Thus, the pooled SMD by random-effect criteria was used to infer the absence of significant differences in the mean values of CAL gain between the two groups $(\mathrm{SMD}=0.734, \mathrm{t}=0.617, p=0.542)$. The overall effect (0.734) was medium (Table 3$)$. The corresponding forest plot for CAL gain shows the effect sizes of each of the two studies and the combined effect size obtained by the fixed- and random effects models (Fig. 3b).

For the third outcome variable "BF," the results showed a statistically significant difference from the control groups in the SMD values with both the fixed-effect and random-effect criteria $(\mathrm{t}=2.673, p=0.013 ; \mathrm{t}=2.673$, $p=0.013$, respectively). Cochran's $\mathrm{Q}$ value was not statistically significant $(\mathrm{Q}=0.2425, p=0.622)$ and the $\mathrm{I}^{2}$ value was $0.00 \%$, which implies the absence of heterogeneity in the two studies included in the analysis. Thus, the pooled SMD obtained by fixed-effect criteria was used to infer a significant difference in the mean values of BF between the two groups $(\mathrm{SMD}=1.189, \mathrm{t}=2.673, p=0.013)$. The overall effect (1.189) was large (Table 3 ). The corresponding forest plot for BF showed the effect sizes of each of the two studies and their combined effect size by the fixed- and random effects models (Fig. 3c) (Table 3).

\section{Three-wall infra-bony defects}

For the outcome variable "PD reduction," the results showed no significant difference in the SMD values obtained by both fixed- and random-effect criteria ( $\mathrm{t}=0.744, p=0.464 ; \mathrm{t}=0.322, p=0.750$, respectively). Cochran's $Q$ value was not statistically significant $(\mathrm{Q}=1.873, p=0.171)$ and the $\mathrm{I}^{2}$ value $(46.61 \%)$ was low and not statistically significant, implying the absence of 
Table 3 Meta-analysis of PD reduction, CAL gain, and bone fill variables related to two-wall infra-bony defects

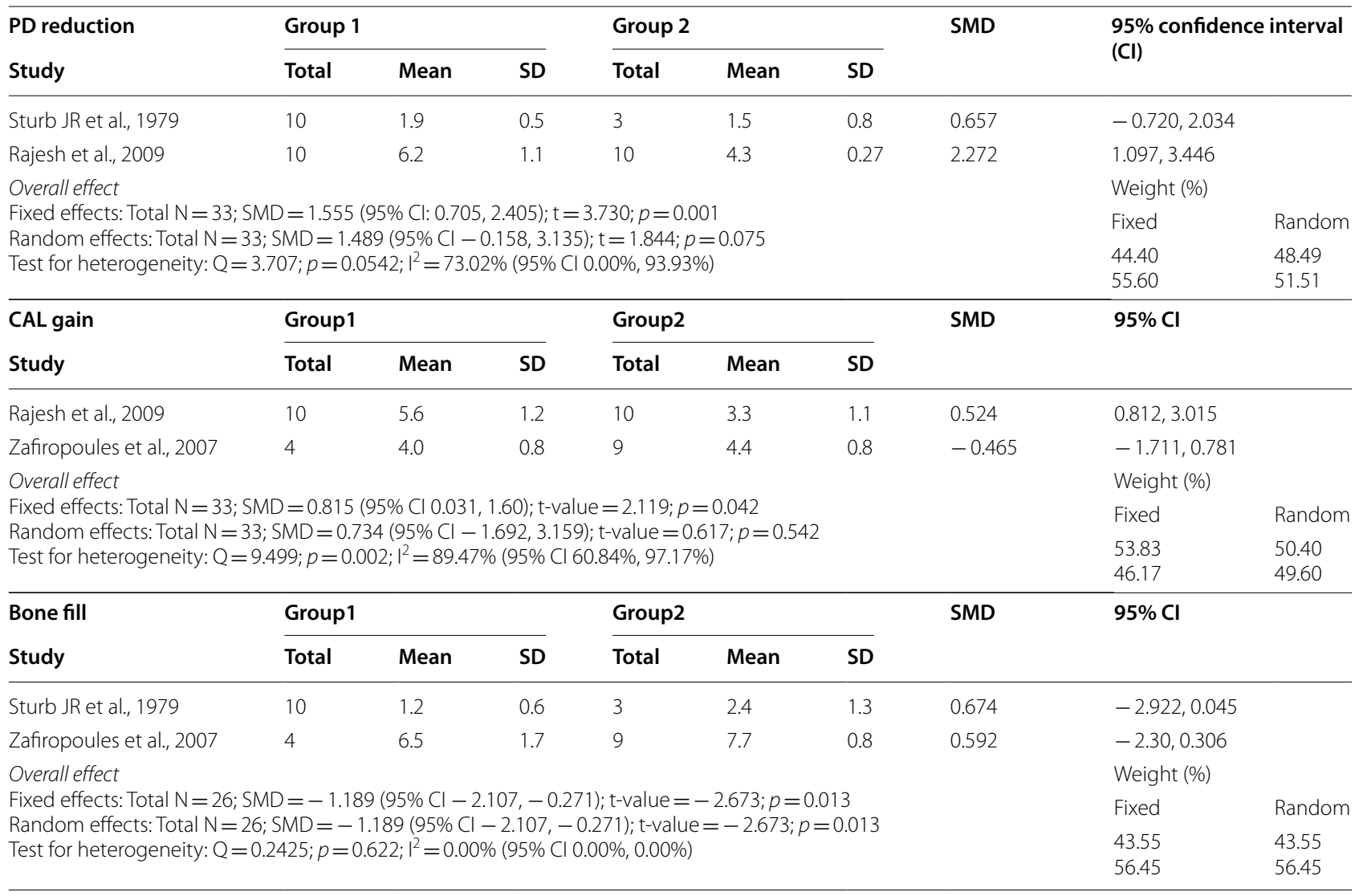

$P D$ pocket depth, SMD standardized mean difference, SD standard deviation, $C A L$ clinical attachment level

heterogeneity in the two studies included in the analysis. Thus, the pooled SMD obtained by fixed-effect criteria was used to infer the absence of significant differences in the mean values of PD reduction between the two groups $(\mathrm{SMD}=0.273, \mathrm{t}=0.744, p=0.464)$. The overall effect $(0.273)$ was low (Table 4). The corresponding forest plot for PD reduction shows the effect sizes of each of the two studies and the combined effect size obtained by the fixed-and random effects models (Fig. 4a).

For the outcome variable "CAL gain," the results showed a statistically significant difference favoring $\beta$-TCP in the SMD values obtained by the fixed-effect but not by the random-effect criteria $(\mathrm{t}=2.206, p=0.031$; $\mathrm{t}=1.376, p=0.173$, respectively). Cochran's $\mathrm{Q}$ value was not statistically significant $(\mathrm{Q}=3.636, p=0.056)$ and the $\mathrm{I}^{2}$ value $(72.50 \%)$ was high, but not statistically significant, which implies that there was no heterogeneity in the two studies included in the analysis. Thus, the pooled SMD obtained by the fixed-effect criteria was used to indicate a significant difference in the mean values of CAL gain between the two groups ( $\mathrm{SMD}=0.532$, $\mathrm{t}=2.206, p=0.031)$. The overall effect $(0.532)$ was medium (Table 4). The corresponding forest plot for CAL gain shows the effect sizes of each of the two studies and the combined effect size obtained by the fixed- and random effects models (Fig. 4b).

For the outcome variable "BF", the results showed a statistically significant difference favoring $\beta$-TCP in the SMD value with only the fixed-effect criteria but not with the random-effect criteria $(\mathrm{t}=3.388, p=0.001$; $\mathrm{t}=0.057, p=0.955$, respectively). Cochran's $\mathrm{Q}$ value was highly statistically significant $(\mathrm{Q}=12.50, p=0.0004)$, and the $\mathrm{I}^{2}$ value $(92.00 \%)$ implied high heterogeneity in the two studies that were included in the analysis. Thus, the pooled SMD obtained by the random-effect criteria was used to infer no statistically significant difference in the mean values of $\mathrm{BF}$ between the two groups $(\mathrm{SMD}=0.088, \mathrm{t}=0.057, p=0.955)$. The overall effect (0.088) was low (Table 4). The corresponding forest plot for BF shows the effect sizes of each of the two studies and the combined effect size by the fixed- and random effects models (Fig. 4c) (Table 4). 

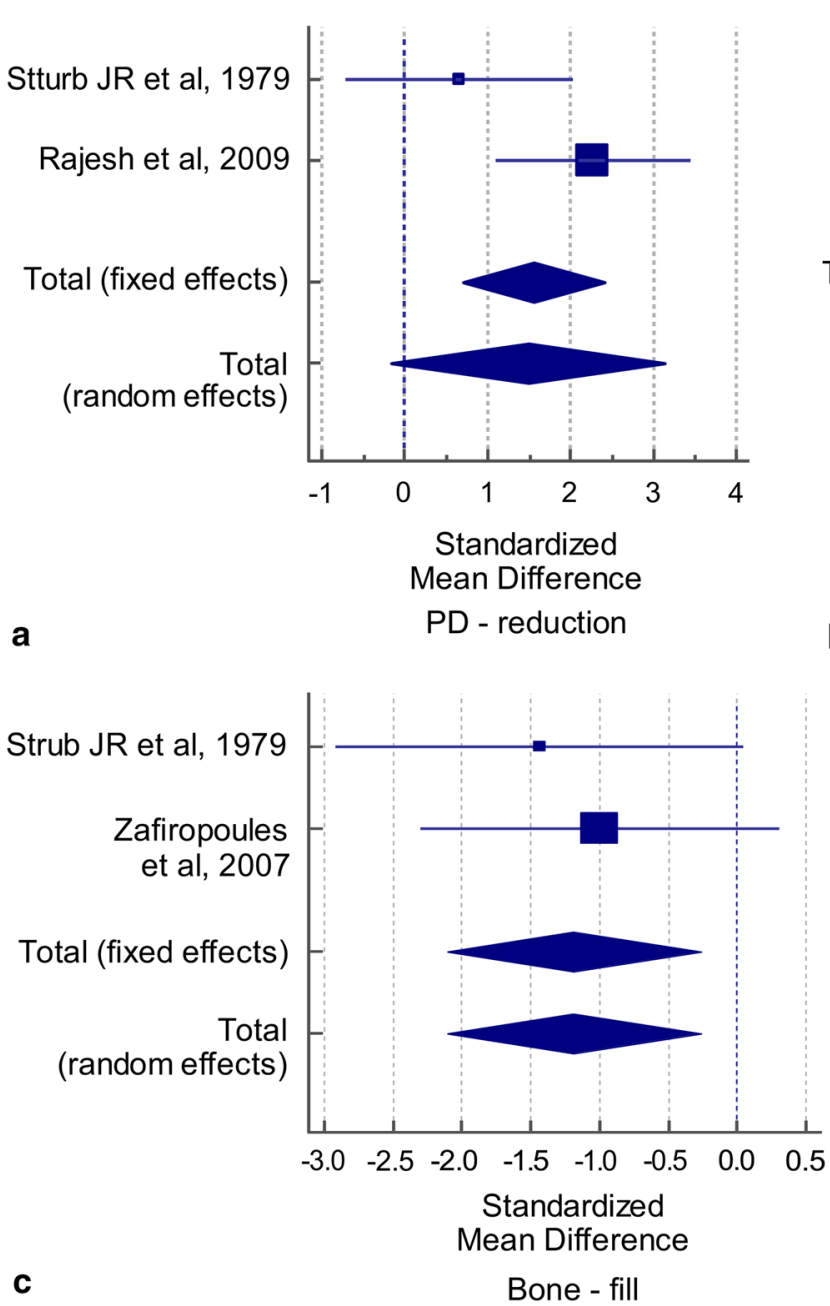

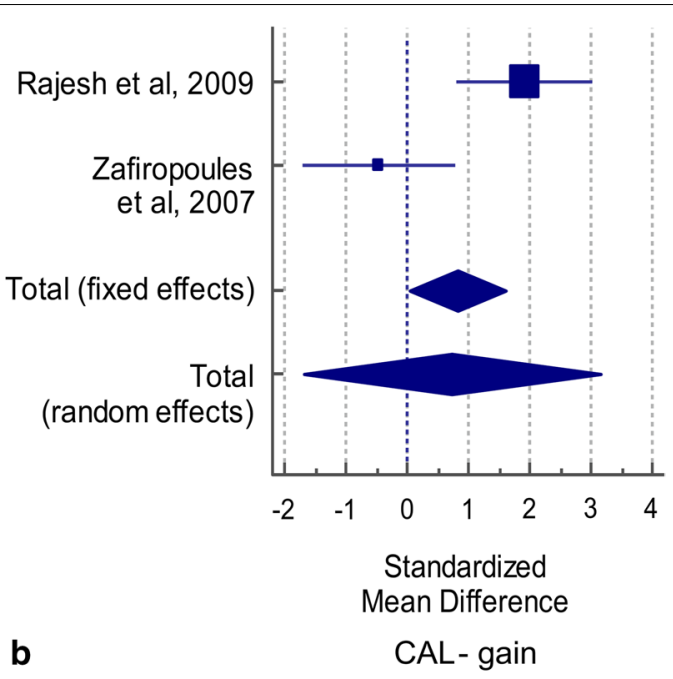

Fig. 3 Forest plot for primary outcome variables for two-wall infra-bony defects a PD reduction, $\mathbf{b}$ CAL gain, $\mathbf{c}$ bone fill

\section{Discussion}

This review and meta-analysis was conducted to evaluate the periodontal regenerative outcomes of using $\beta$-TCP alloplast for treating infra-bony defects and to compare the findings with those obtained after using other grafting or regenerative materials. This extensive literature search revealed that very few studies had been performed on this alloplastic material. Only five studies were included in this systematic review, three of these had been classified as showing a low risk of heterogeneity and were involved in the meta-analysis. Overall, $\beta$-TCP demonstrated favorable results compared to debridement alone. However, using it alone or in combination with other bone substitutes showed outcomes comparable to those with other treatment modalities and grafting materials. Furthermore, the meta-analysis revealed that for two-wall defects, the use of $\beta$-TCP was associated with a significant difference in PD reduction and CAL gain; BF did not show such a change. However, for threewall defects, while no statistically significant difference was observed in PD reduction with both random- and fixed-effect models, CAL gain and BF showed statistically significant differences favoring the use of $\beta$-TCP in the fixed-effect model. Overall, all outcome measures showed comparable results for $\beta$-TCP and all other treatment modalities and grafting materials used. The amount of $\mathrm{PD}$ reduction, CAL gain, and BF was slightly inferior to those with autogenous and allografts only, in comparison with the fixed-effect meta-analysis model. Similar results have been reported by Calin et al., who noted that the $\beta$-TCP group showed comparable PD reduction, CAL gain, and $\mathrm{BF}$ as autogenous and allogenous grafts [25]. In 
Table 4 Meta-analysis of PD reduction, CAL gain, and bone fill variables related to three-wall infra-bony defects

\begin{tabular}{|c|c|c|c|c|c|c|c|c|c|}
\hline \multirow{2}{*}{$\begin{array}{l}\text { PD reduction } \\
\text { Study }\end{array}$} & \multicolumn{3}{|c|}{ Group 1} & \multicolumn{3}{|c|}{ Group 2} & \multirow[t]{2}{*}{ SMD } & \multicolumn{2}{|c|}{$95 \%$ confidence interval $(\mathrm{Cl})$} \\
\hline & Total & Mean & SD & Total & Mean & SD & & & \\
\hline Sturb JR et al., 1979 & 3 & 1.9 & 0.6 & 3 & 1.5 & 0.7 & 0.667 & $-1.361,2.340$ & \\
\hline Rajesh et al., 2009 & 10 & 3.5 & 1.2 & 10 & 4.5 & 1.9 & 0.439 & $-1.524,0.319$ & \\
\hline \multirow{3}{*}{\multicolumn{7}{|c|}{$\begin{array}{l}\text { Overall effect } \\
\text { Fixed effects: Total } \mathrm{N}=26 ; \mathrm{SMD}=-0.273(95 \% \mathrm{Cl}-1.029,0.484) ; \mathrm{t}=-0.744 ; p=0.464 \\
\text { Random effects: Total } \mathrm{N}=26 ; \mathrm{SMD}=-0.172(95 \% \mathrm{Cl}-1.274,0.930) ; \mathrm{t}=-0.322 ; p=0.750 \\
\text { Test for heterogeneity: } \mathrm{Q}=1.873 ; p=0.171 ; \mathrm{I}^{2}=46.61 \%(95 \% \mathrm{Cl} 0.00 \%, 0.00 \%)\end{array}$}} & & \multicolumn{2}{|l|}{ Weight (\%) } \\
\hline & & & & & & & & Fixed & Random \\
\hline & & & & & & & & $\begin{array}{l}30.22 \\
69.78\end{array}$ & $\begin{array}{l}39.44 \\
60.56\end{array}$ \\
\hline \multirow{2}{*}{$\begin{array}{l}\text { CAL gain } \\
\text { Study }\end{array}$} & \multicolumn{3}{|c|}{ Group 1} & \multicolumn{3}{|c|}{ Group 2} & \multirow[t]{2}{*}{ SMD } & \multirow{2}{*}{\multicolumn{2}{|c|}{$95 \% \mathrm{Cl}$}} \\
\hline & Total & Mean & SD & Total & Mean & $\overline{S D}$ & & & \\
\hline Rajesh et al., 2009 & 10 & 5.9 & 1.2 & 10 & 3.8 & 1.8 & 1.315 & $0.315,2.315$ & \\
\hline Zafiropoules et al., 2007 & 25 & 4.7 & 0.8 & 25 & 4.5 & 0.7 & 0.262 & $-0.300,0.824$ & \\
\hline \multirow{3}{*}{\multicolumn{7}{|c|}{$\begin{array}{l}\text { Overall effect } \\
\text { Fixed effects: Total } \mathrm{N}=35 ; \mathrm{SMD}=0.532(95 \% \mathrm{Cl} 0.051,1.013) ; \mathrm{t} \text {-value }=2.206 ; p=0.031 \\
\text { Random effects: Total } \mathrm{N}=35 ; \mathrm{SMD}=0.718(95 \% \mathrm{Cl}-0.323,1.759) ; \mathrm{t} \text {-value }=1.376 ; p=0.173 \\
\text { Test for heterogeneity: } \mathrm{Q}=3.636 ; p=0.056 ; I^{2}=72.50 \%(95 \% \mathrm{Cl} 0.00 \%, 93.81 \%)\end{array}$}} & & \multicolumn{2}{|l|}{ Weight (\%) } \\
\hline & & & & & & & & Fixed & Random \\
\hline & & & & & & & & $\begin{array}{l}25.65 \\
74.35\end{array}$ & $\begin{array}{l}43.30 \\
56.70\end{array}$ \\
\hline \multirow{2}{*}{$\begin{array}{l}\text { Bone fill } \\
\text { Study }\end{array}$} & \multicolumn{3}{|c|}{ Group 1} & \multicolumn{3}{|c|}{ Group 2} & \multirow[t]{2}{*}{ SMD } & \multirow{2}{*}{\multicolumn{2}{|c|}{$95 \% \mathrm{Cl}$}} \\
\hline & Total & Mean & $\overline{S D}$ & Total & Mean & $\overline{S D}$ & & & \\
\hline Sturb JR et al., 1979 & 3 & 1.2 & 0.5 & 3 & 2.4 & 0.6 & -1.734 & $-4.015,0.547$ & \\
\hline Zafiropoules et al., 2007 & 25 & 7.7 & 0.9 & 25 & 6.3 & 1.1 & 1.371 & $0.747,1.995$ & \\
\hline \multirow{3}{*}{\multicolumn{7}{|c|}{$\begin{array}{l}\text { Overall effect } \\
\text { Fixed effects: Total } \mathrm{N}=56 ; \mathrm{SMD}=0.983(95 \% \mathrm{Cl} 0.401,1.565) ; \mathrm{t} \text {-value }=3.388 ; p=0.001 \\
\text { Random effects: Total } \mathrm{N}=56 ; \mathrm{SMD}=-0.088(95 \% \mathrm{Cl}-3.195,3.019) ; \mathrm{t}-\mathrm{value}=-0.057 ; p=0.955 \\
\text { Test for heterogeneity: } \mathrm{Q}=12.500 ; p=0.0004 ; I^{2}=92.00 \%(95 \% \mathrm{Cl} 72.42 \%, 97.68 \%)\end{array}$}} & & \multicolumn{2}{|l|}{ Weight (\%) } \\
\hline & & & & & & & & Fixed & Random \\
\hline & & & & & & & & $\begin{array}{l}12.49 \\
87.51\end{array}$ & $\begin{array}{l}47.00 \\
53.00\end{array}$ \\
\hline
\end{tabular}

$P D$ pocket depth, $S M D$ standardized mean difference, $S D$ standard deviation, $C A L$ clinical attachment level

contrast, in a previous systematic review comparing the amount of BF using autografts, allografts, xenografts, and alloplasts, BF was slightly inferior in the alloplast groups, compared with the other groups [26].

Furthermore, we compared the outcomes of $\beta$-TCP in this review with those of another well-documented alloplastic material, HA. A recent systematic review showed no significant difference between the use of HA and open-flap debridement and concluded that the clinical effectiveness of HA in treating periodontal bony defect regeneration is unclear. However, the combination of HA with $\beta$-TCP showed significant improvement in bone defect regeneration [27].

Overall, the autografts and allografts showed superior results in terms of regeneration, especially with more challenging defects such as two-wall defects, as they were less predictable and required an additional focused approach to successful regenerative outcomes. $\beta$-TCP is a promising alternative regenerative material in situations where optimum grafts cannot be used due to unavailability or cost issues. Furthermore, it is possible to enhance $\beta$-TCP outcomes when combined with other types of alloplasts or growth factors to achieve similar outcomes to autografts and allografts [25-28].

This systematic review has several limitations, including the limited number of studies, lack of randomized clinical trials, and small sample sizes of the included studies.

\section{Conclusions}

The findings of this systematic review and meta-analysis suggest that $\beta$-TCP is a promising alternative to bone substitute material when used in treating periodontal infra-bony defects around natural teeth, warranting further exploration and investigation in comparative assessments. Additional randomized controlled trials focusing on $\beta$-TCP are required to confirm the current findings. 


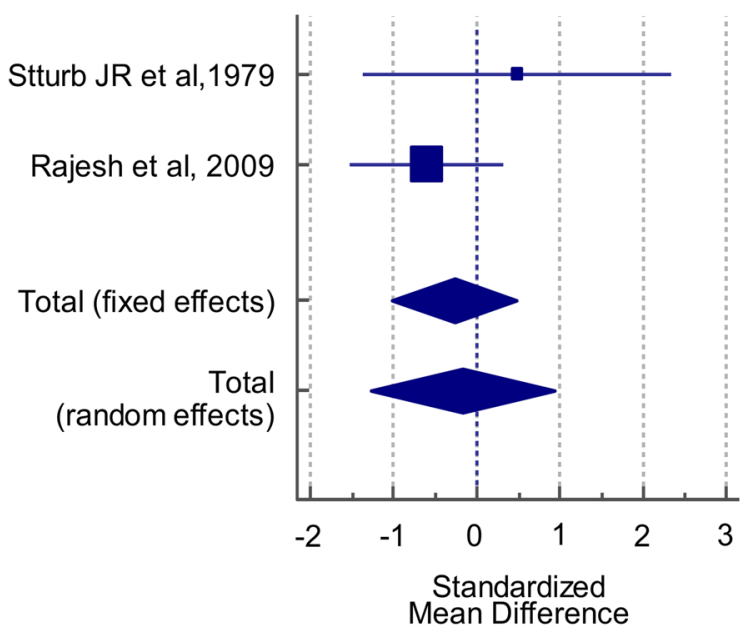

a

PD - reduction





CAL-gain

C

Bone - fill

Fig. 4 Forest plot for primary outcome variables of three-wall infra-bony walls defects

\section{Abbreviations}

$\beta$-TCP: $\beta$-Tricalcium phosphate; ASB: Autogenous spongiosa; CAL: Clinical attachment level; GR: Gingival recession; GTR: Guided tissue regeneration; HA: Hydroxyapatite; KTW: Keratinized tissue width; PD: Probing depth; STT: Soft tissue thickness; SMD: Standardized mean difference.

\section{Acknowledgements}

Not applicable.

\section{Authors' contributions}

R.J. initiated the aim and idea for the present study, F.S. and A. S. had conducted the data searching process, data extraction, and table constructions as well risk-of-bias assessment. Meta-analysis was performed by R.J. and the final manuscript write-up and revision were done by all authors in an equal manner. All authors read and approved the final manuscript.
Availability of data and materials

The datasets used and/or analyzed during the current study are available from the corresponding author on reasonable request.

\section{Declarations}

Ethics approval and consent to participate Not applicable.

\section{Consent for publication}

Not applicable.

\section{Competing interests}

The authors declare that they have no competing interests.

\section{Funding}

None. 


\section{Author details}

${ }^{1}$ Associate Professor, Department of Periodontics and Community Dentistry, Dental College, King Saud University, PO Box 60169, Riyadh 11545, Saudi Arabia. ${ }^{2}$ Saudi Board Resident, Ministry of Health, Riyadh, Saudi Arabia.

Received: 11 August 2020 Accepted: 14 April 2021

Published online: 29 April 2021

\section{References}

1. Ana ID. Bone substituting materials in dental implantology. In: Budihardja A, Mücke T, editors. Bone management in dental implantology. New York: Springer; 2019.

2. Driskell TD, Hassler CR, McCoy LR. The significance of resorbable bioceramics in the repair of bone defect. Proc Annu Conf Eng Med Biol. 1973;15:119.

3. Ana ID, Satria GAP, Dewi AH, Ardhani R. Bioceramics for clinical application in regenerative dentistry. Adv Exp Med Biol. 2018;1077:309-16.

4. Heller AL, Koenigs JF, Brilliant JD, Melfi RC, Driskell TD. Direct pulp capping of permanent teeth in primates using a resorbable form of tricalcium phosphate ceramic. J Endod. 1975;1 (3):95-101.

5. Mors WA, Kaminski EJ. Osteogenic replacement of tricalcium phosphate ceramic implants in the dog palate. Arch Oral Biol. 1975;20(5-6):365-7.

6. Ferraro JW. Experimental evaluation of ceramic calcium phosphate as a substitute for bone grafts. Plast Reconstr Surg. 1979;63(5):634-40.

7. Levin MP, Getter L, Cutright DE, Bhaskar SN. Biodegradable ceramic in periodontal defects. Oral Surg Oral Med Oral Pathol. 1974;38(3):344-51.

8. Cameron HU, Macnab I, Pilliar RM. Evaluation of a biodegradable ceramic. J Biomed Mater Res. 1977;11(2):179-86.

9. Saito H, Shiau HJ, Prasad H, Reynolds MA. Evaluation of a poly(lactic-coglycolic) acid-coated $\beta$-tricalcium phosphate bone substitute for alveolar ridge preservation: case series. Clin Adv Periodontics. 2017;7:190-4.

10. Metsger DS, Driskell TD, Paulsrud JR. Tricalcium phosphate ceramic - a resorbable bone implant: review and current status. J Am Dent Assoc. 1982;105(6):1035-8.

11. Snyder AJ, Levin MP, Cutright DE. Alloplastic implants of tricalcium phosphate ceramic in human periodontal osseous defects. J Periodontol. 1984;55(5):273-7.

12. Bowers GM, Vargo JW, Levy B, Emerson JR, Bergquist JJ. Histologic observations following the placement of tricalcium phosphate implants in human intrabony defects. J Periodontol. 1986;57(5):286-7.

13. Kim S, Hu K-S, Jung U-W. Reosseointegration after regenerative surgical therapy using a synthetic bone substitute for peri-implantitis: human autopsy study. Int J Periodontics Restorative Dent. 2018;38(4):585-91.

14. Kishore DT, Bandiwadekar T, Padma R, Debunath S, Profulla A, Reddy A. Evaluation of relative efficacy of $\beta$-tricalcium phosphate with and without type 1 resorbable collagen membrane in periodontal infrabony defects: a clinical and radiographic study. J Contemp Dent Pract. 2013;14(2):193-201.

15. Saini N, Sikri P, Gupta H. Evaluation of the relative efficacy of autologous platelet-rich plasma in combination with $\beta$-tricalcium phosphate alloplast versus an alloplast alone in the treatment of human periodontal infrabony defects: a clinical and radiological study. Indian J Dent Res. 2011:22(1):107-15.

16. Kurkcu M, Benlidayi ME, Cam B, Sertdemir Y. Anorganic bovine-derived hydroxyapatite versus $\beta$-tricalcium phosphate in sinus augmentation. A comparative histomorphometric study. J Oral Implantol. 2012;2012:120522093526004

17. Mardas N, D’Aiuto F, Mezzomo L, Arzoumanidi M, Donos N. Radiographic alveolar bone changes following ridge preservation with two different biomaterials. Clin Oral Implants Res. 2011;22(4):416-23.

18. Tosta M, Cortes ARG, Corrêa L, dos Pinto DS, Tumenas I, Katchburian E. Histologic and histomorphometric evaluation of a synthetic bone substitute for maxillary sinus grafting in humans. Clin Oral Implants Res. 2013:24(8):866-70.

19. Moher D, Liberati A, Tetzlaff J, Altman DG, Altman D, Antes G, et al. Preferred reporting items for systematic reviews and meta-analyses: the PRISMA statement. PLoS Med. 2009;6:e1000097.

20. Cohen J. Weighted kappa: nominal scale agreement provision for scaled disagreement or partial credit. Psychol Bull. 1968;70(4):213-20.

21. Strub JR, Gaberthüel TW, Firestone AR. Comparison of tricalcium phosphate and frozen allogenic bone implants in man. J Periodontol. 1979;50(12):624-9.

22. Zafiropoulos G-GK, Hoffmann O, Kasaj A, Willershausen B, Weiss O, Van Dyke TE. Treatment of intrabony defects using guided tissue regeneration and autogenous spongiosa alone or combined with hydroxyapatite/ $\beta$ tricalcium phosphate bone substitute or bovine-derived xenograft. J Periodontol. 2007;78(11):2216-25.

23. Rajesh JB, Nandakumar K, Varma HK, Komath M. Calcium phosphate cement as a "barrier-graft" for the treatment of human periodontal intraosseous defects. Indian J Dent Res. 2009;20(4):471-9.

24. Sukumar S, Drízhal I, Bukac J, Paulusová V, Pilathadka S. Surgical treatment of periodontal intrabony defects with calcium sulphate in combination with beta tricalcium phosphate-a 12-month retrospective clinical evaluation. Acta Medica (Hradec Kralove). 2010;53:229-34.

25. Cãlin C, Pãtrascu I. Growth factors and beta-tricalcium phosphate in the treatment of periodontal intraosseous defects: a systematic review and meta-analysis of randomised controlled trials. Arch Oral Biol. 2016:66:44-54.

26. Sculean A, Nikolidakis D, Nikou G, Ivanovic A, Chapple ILC, Stavropoulos A. Biomaterials for promoting periodontal regeneration in human intrabony defects: a systematic review. Periodontol. 2015;68(1):182-216.

27. Dewi AH, Ana ID. The use of hydroxyapatite bone substitute grafting for alveolar ridge preservation, sinus augmentation, and periodontal bone defect: a systematic review. Heliyon. 2018;4(10):e00884.

28. Reynolds MA, Aichelmann-Reidy ME, Branch-Mays GL, Gunsolley JC. The efficacy of bone replacement grafts in the treatment of periodontal osseous defects. A systematic review. Ann Periodontol. 2003;8(1):227-65.

\section{Publisher's Note}

Springer Nature remains neutral with regard to jurisdictional claims in published maps and institutional affiliations.
Ready to submit your research? Choose BMC and benefit from:

- fast, convenient online submission

- thorough peer review by experienced researchers in your field

- rapid publication on acceptance

- support for research data, including large and complex data types

- gold Open Access which fosters wider collaboration and increased citations

- maximum visibility for your research: over 100M website views per year

At BMC, research is always in progress.

Learn more biomedcentral.com/submissions 